\title{
BMJ Open Development and validation of an instrument for measuring the burden of medicine on functioning and well- being: the Medication-Related Burden Quality of Life (MRB-QoL) tool
}

\author{
Mohammed A Mohammed, ${ }^{1}$ Rebekah J Moles, ${ }^{1}$ Sarah N Hilmer, ${ }^{2,3}$ \\ Lisa Kouladjian O'Donnel, ${ }^{2,3}$ Timothy F Chen ${ }^{1}$
}

To cite: Mohammed MA, Moles RJ, Hilmer SN, et al. Development and validation of an instrument for measuring the burden of medicine on functioning and well-being: the MedicationRelated Burden Quality of Life (MRB-QoL) tool. BMJ Open 2018;8:e018880. doi:10.1136/ bmjopen-2017-018880

- Prepublication history and additional material for this paper are available online. To view please visit the journal (http:// dx.doi.org/10.1136/bmjopen2017-018880).

Received 28 July 2017 Revised 30 September 2017 Accepted 25 October 2017

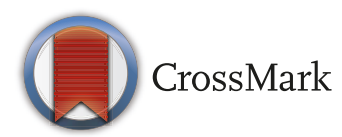

${ }^{1}$ Faculty of Pharmacy, University of Sydney, Sydney, New South Wales, Australia

${ }^{2}$ Department of Clinical

Pharmacology and Aged Care, Royal North Shore Hospital, Kolling Institute of Medical Research, Sydney, New South Wales, Australia

${ }^{3}$ Cognitive Decline Partnership Centre, Sydney Medical School, University of Sydney, Sydney, New South Wales, Australia

Correspondence to

Mohammed A Mohammed;

mmoh2116@uni.sydney.edu.au

\section{ABSTRACT}

Objective Medication-related burden (MRB) is a

negative experience with medicine, which may impact on psychological, social, physical and financial well-being of an individual. This study describes the development and initial validation of an instrument specifically designed to measure MRB on functioning and well-being - the Medication-Related Burden Quality of Life (MRB-QoL) tool.

Methods An initial pool of 76-items for MRB-QoL was generated. The link to MRB-QoL survey was sent to a sample of consumers living with at least one chronic medical condition and taking $\geq 3$ prescription medicines on a regular basis. Exploratory factor analysis (EFA) was used to determine the underlining factor structure. Internal consistency (Cronbach's $\alpha$ ) and construct validity were examined. The latter was examined through correlation with Medication Regimen Complexity Index (MRCl), Drug Burden Index (DBI) and Charlson's Comorbidity Index (CCl).

Results 367 consumers completed the survey $(51.2 \%$ male). EFA resulted in a 31-item, five-factor solution explaining $72 \%$ of the total variance. The five subscales were labelled as 'Routine and Regimen Complexity' (11 items), 'Psychological Burden' (six items), 'Functional and Role Limitation' (seven items), 'Therapeutic Relationship' (three items) and 'Social Burden' (four items). All subscales showed good internal consistency (Cronbach's $\alpha 0.87$ to 0.95 ). Discriminant validity of MRB-QoL was demonstrated via its correlations with MRCI (Spearman's $r-0.16$ to 0.08$), \mathrm{DBI}$ ( $r 0.12$ to 0.28$)$ and $\mathrm{CCl}(r-0.23$ to $-0.15)$. Correlation between DBI and 'Functional and Role Limitation' subscale ( $r 0.36$ ) indicated some evidence of convergent validity. Patients with polypharmacy, multiple morbidity and $\mathrm{DBI}>0$ had higher median scores of MRBQoL providing evidence for known group validity.

Conclusions The MRB-QoL V.1 has good construct validity and internal consistency. The MRB-QoL may be a useful humanistic measure for evaluating the impact of pharmaceutical care interventions on patients' quality of life. Future research is warranted to further examine additional psychometric properties of MRB-QoL V.1 and its utility in patient care.

\section{Strengths and limitations of this study}

- This study described the development and validation of the Medication-Related Burden Quality of Life (MRB-QoL) tool based on robust methods and highlighted its potential application for research and practice.

- MRB-QoL V.1 has good construct validity and internal consistency.

- The MRB-QoL can be used to facilitate evaluation of humanistic outcome in pharmaceutical care interventions.

- This tool fills a need in pharmacotherapy research and has also a potential for use as a screening tool in clinical practice to identify patients at high risk of experiencing medication-related burden.

- Validation of a patient-reported measure cannot be completed in a single study; thus, MRB-QoL requires further validation such as confirmatory factor analysis, test-retest reliability, sensitivity and responsiveness.

\section{INTRODUCTION}

Medicines represent the most common form of therapy in the management of chronic medical conditions. ${ }^{1}$ Clinical management of various chronic medical conditions often requires prescribing of multiple medicines especially in people with multimorbidity. ${ }^{2}$ Although medicines usually improve patient health outcomes, for some patients, longterm use of multiple medicines may become burdensome $^{1}$ and have negative consequences. ${ }^{3}$ Patients often experience medication-related burden (MRB) because of the routines associated with taking medicines, adverse events, nature of medicines (eg, inconvenience or complexity of the regimen), challenges associated with the healthcare system (eg, access to medicines) and interference with social activities. ${ }^{1}$ The encountered 
MRB can adversely affect the social, psychological and physical well-being of an individual. ${ }^{13-5}$ Patients experiencing MRB often report poor health-related quality of life (HRQoL). ${ }^{156}$

Improving a patient's HRQoL outcome is an ultimate goal of 'pharmaceutical care' (PC) services ${ }^{7}$ defined as 'responsible provision of drug therapy for the purpose of achieving definite outcomes that improve a patient's quality of life'. PC is medication therapy focused healthcare provided to achieve improved medication therapy and quality of life for patients. The social, psychological and physical impact of medication therapy on patients' lives is a critical humanistic dimension that should be evaluated in all PC interventions. ${ }^{8}$ However, it is not known how the core elements of PC interventions (ie, identification and resolution of drug-related problems) are linked to changes in humanistic outcomes. ${ }^{9}$ Thus, demonstrating the full picture of the benefit of PC services in improving patients' HRQoL outcomes remains challenging. Existing evidence is inconclusive and conflicting. ${ }^{10-21}$ The lack of sensitivity and specificity of existing HRQoL measures to capture the humanistic outcome aspects related to the impact of drug therapy may be a contributing factor. ${ }^{8172223}$

Over the last three decades, outcomes of HRQoL in PC research have been evaluated using generic and/or disease-specific HRQoL measures. ${ }^{17}{ }^{23-25}$ These measures, however, have been developed to evaluate the impact of disease burden on patients' life, not specifically the impact of pharmacotherapy. ${ }^{172}$ Our recent systematic review and content analysis showed that out of the total 1019 items identified from 37 HRQoL measures used in PC studies published between 1990 and 2015, only 34 items were specifically about medicines. ${ }^{23}$ This review further highlighted that items about medicines did not appear to have been focused on the burden of medicines on functioning and well-being. This implies that existing HRQoL measures lack specificity to PC services and sensitivity to detect changes in HRQoL caused by the burden of medicines.

Other widely used measures of medication burden such as Drug Burden Index (DBI) ${ }^{26}$ and Medication Regimen Complexity Index (MRCI) ${ }^{27}$ are useful objective measures of the burden of medicines. However, neither is a patient-reported and a humanistic measure. There is currently no validated measure of Medication-Related Burden on quality of life. This study reports on the development and preliminary validation of an instrument specifically designed to measure the burden of medicine on functioning and well-being from the patient's perspective.

\section{METHODS}

\section{Development of the MRB-QoL tool}

The Medication-Related Burden Quality of Life (MRBQoL) tool was developed in three phases (figure 1). Phase I involved: conceptualisation of the area through meta-synthesis of MRB and patients' lived experience with medicines, ${ }^{1}$ meta-analysis of pharmaceutical care (PC) impact on HRQoL, ${ }^{17}$ content analysis of HRQoL measures used in PC studies. ${ }^{23}$ Phase II involved: the generation and refinement of an item pool. Phase III involved: the psychometric testing of the items using responses from a sample of Australian health and medicines consumers.

\section{Item pool}

Meta-synthesis of 34 qualitative studies about patients' lived experience with medicine provided a core

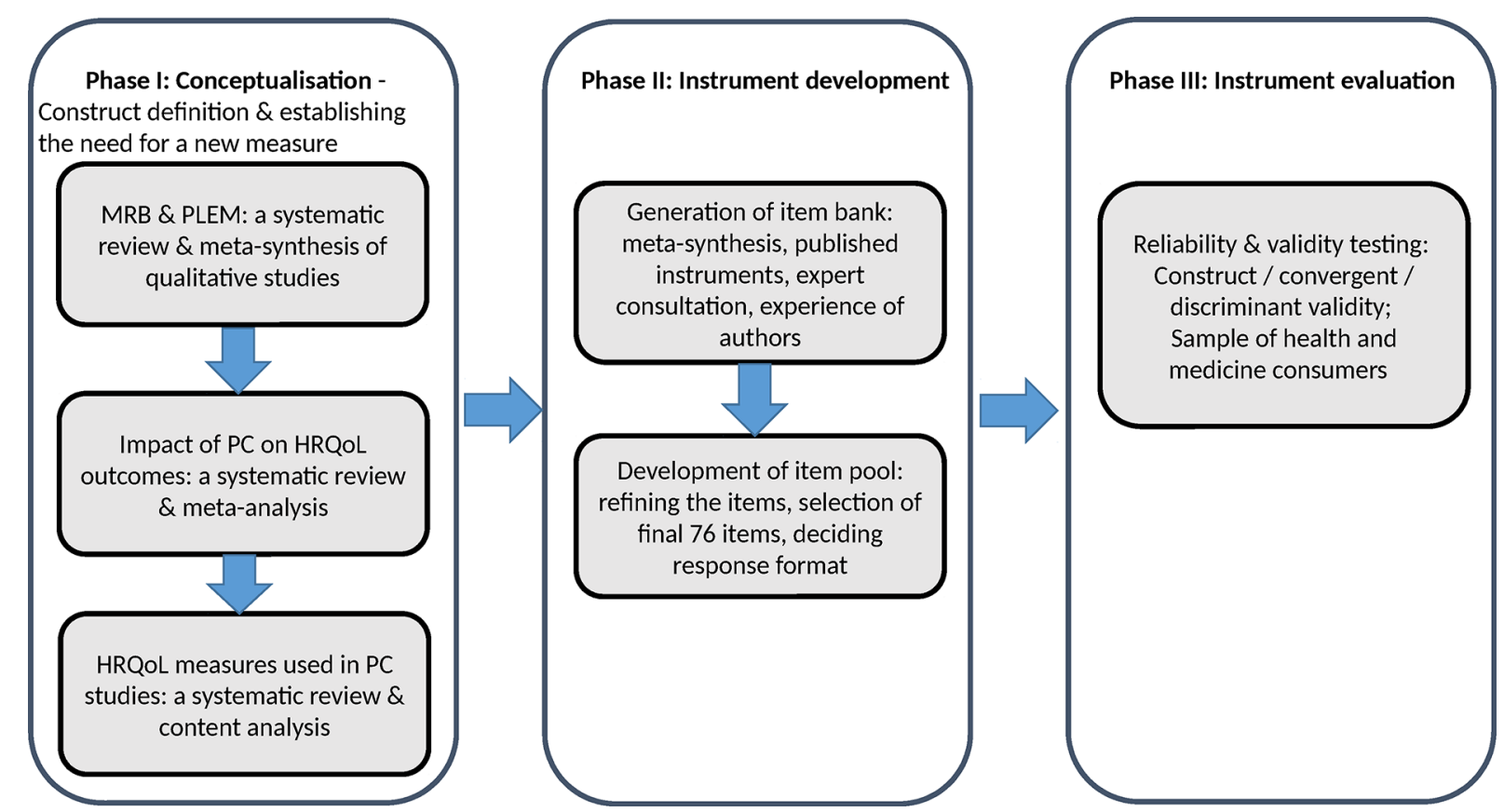

Figure 1 Development and validation process of the MRB-QoL tool. HRQoL, health-related quality of life; MRB-QoL, Medication-Related Burden Quality of Life; PC, pharmaceutical care; PLEM, patients' lived experience with medicine. 
foundation for item generation. ${ }^{1}$ Over 966 quotes of patients were identified through meta-synthesis and used as a source to generate an item bank. We believed that generation of a pool of items via this approach was advantageous in establishing a strong conceptual foundation and theoretical understanding, when compared with traditional methods of item generation based on an interview with a single cohort of participants. It was anticipated that this approach may be more comprehensive in generating a pool of items covering a wide range of medicine-associated burden across multiple chronic illnesses. We used Nvivo 10 (QRS International, Victoria) Software to facilitate coding and analysis of participants' quotes. ${ }^{1}$ Following analyses of coded data, a pool of 76 items representing relevant medicine associated burden were generated. A theoretical conceptual framework of MRB-QoL (see online supplementary file 1) was used to guide the item development process. The framework was developed based on the themes of MRB identified in our meta-synthesis, ${ }^{1}$ recommended domains of HRQoL in evaluation of PC services ${ }^{817}$ and conceptual gaps in the HRQoL measures used in PC interventions. ${ }^{323}$ Quality of life instruments specifically designed to evaluate PC services should encompass at least physical, social and psychological domains. ${ }^{8} 17$ Several existing HRQoL measures used in the evaluation of PC interventions encompass these three domains, however, the domains lack items about the burden of medicine on health and well-being. ${ }^{17}{ }^{23}$ In light of this, items of MRB-QoL were designed in a way to typically focus on medication burden ranging from the inconvenience of dealing with routines to the burden on social, psychological, physical and financial well-being.

\section{Study sample and data collection}

A consumer panel fulfilling the inclusion criteria was recruited via an Australian market research company, the Survey Sampling International. Consumers had to be 18 years or older, taking $\geq 3$ prescription medicines on a regular basis and living with at least one medical condition. The estimated sample size $(n=380)$ was calculated using 5:1 ratio, that is, five participants per item. ${ }^{28}{ }^{29}$ The market research company distributed a survey monkey link to the MRB-QoL to potential participants. Screening questions were used to allow only eligible participants (based on age, number of medicines and medical conditions) to complete the survey. Eligible participants were asked to indicate on a five-point Likert scale the extent to which they agreed or disagreed with each statement of MRB-QoL tool where, '1=strongly agree', '2=agree', ' $3=$ neither agree nor disagree', '4=disagree' and ' $5=$ strongly disagree'. In addition, 'prefer not to answer' was included as an alternative option to respect participants' choice of not responding to a given item. A 2-week recall period was used to help participants recall relevant experience associated with specific aspects of medicine burden, for example, 'considering the impact of your medicine on your physical well-being during the past 2 weeks, indicate how much you agree or disagree with the following statement?'. The survey also had an open-ended section for participants to document names of medical conditions and, names of medicines, their strengths and directions for use. Participants were asked to complete sections about medicines (prescribed by doctors and obtained over the counter) only when they were at home and had complete access to their medicines.

\section{Data analyses}

Characteristics of study participants were summarised using descriptive statistics. Tests for normality (Shapiro Wilk test, Q-Q plot, Box plot, Histogram, skewness and kurtosis) showed that the analysed variables were not normally distributed. Hence, continuous variables were summarised using medians and range whereas categorical variables were reported using frequencies and percentages. Exploratory factor analysis (EFA) using oblique rotation was conducted to determine the factor structure underlying MRB-QoL. An oblique method of factor rotation was chosen because of expected correlation among the factors. ${ }^{3031}$ Before factor analysis, suitability of the data for factor analysis was checked using Kaiser-Mayer Olkin measure of sampling adequacy (value $>0.8$ ), Bartlett's test of sphericity $(\mathrm{P}<0.01)$ and inspection of the correlation matrix for coefficients $\geq 0.3 .{ }^{28}$ An initial factor solution was determined by visual inspection of scree plots and Eigen values $>1$. Final items were retained based on factor loadings $(>0.3)$, no cross loadings on two or more factors $(>0.3)$, item-total correlations and interpretability with regard to extracted factors. Cronbach's alpha coefficient was used to assess internal consistency reliability. ${ }^{32}$ Testing convergent (moderate to high correlations, ie, $r>0.3)^{33}$ and discriminant (weak correlations, ie, $r \leq 0.3$ ) validity of MRB-QoL in relation to DBI (measure of exposure to medicines with anticholinergic and sedative effects), MRCI (measure of complexity of medicine regimen) and Charlson's Comorbidity Index (CCI) (measure of disease burden) was planned where data were available (ie, detailed information about name of medicine, strengths and directions for use and detailed information on diagnoses). We hypothesised that domains of MRB-QoL would be positively correlated with DBI, MRCI and CCI, but the MRB-QoL is a separate concept from all the three indices. Similarly, with an a priori assumption that patients on polypharmacy ( $\geq 5$ different medicines), ${ }^{34}$ with multimorbidity ( $\geq 3$ different medical conditions) $)^{35-39}$ and DBI $>0$ may have poorer MRB-QoL, we planned to test known group validity of the MRB-QoL if sufficient data were available for these variables. MRCI was calculated as the sum of scores of dosage forms used, dosage frequency and additional instructions. ${ }^{27}$ DBI for each participant was calculated as the sum of exposure to each medicine with anticholinergic or sedative effects ${ }^{26}$ taking into account the total daily dose and the recommended minimum daily dose by the Therapeutic Goods Administration of Australia. ${ }^{40}$ Australian approved lists of medicines were used to define medicines with clinically 
Table 1 Characteristics of survey respondents $(n=367)$

\begin{tabular}{lc}
\hline Characteristic & Value \\
\hline Age in years (IQR) & $64(49-70)$ \\
Male gender, $n(\%)$ & $188(51.2)$ \\
\hline Number of medical conditions (IQR) & $3(2-3)$ \\
\hline Number of prescription medicines (IQR) & $5(3-7)$ \\
\hline Number of over the counter medicines (IQR) & $2(1-3)$ \\
CCI (IQR) & $3(0-4)$ \\
MRCI (IQR) & $9(7-13)$ \\
\hline Total DBI (IQR) & $0.5(0-0.9)$ \\
\hline DBI>0 (IQR) & $0.9(0.7-1.6)$ \\
\hline Age <65years, median (IQR) & $1.2(1.01)$ \\
\hline Age $\geq 65$ years median (IQR) & $0.7(0.8)$ \\
DBI categories & \\
\hline DBI 0, n (\%) & $132(47.1)$ \\
\hline DBI 0-1, n (\%) & $67(28.9)$ \\
DBI >1, n (\%) & $67.9)$ \\
\hline
\end{tabular}

CCI, Charlson's Comorbidity Index; DBI, Drug Burden Index; $\mathrm{MRCl}$, Medication Regimen Complexity Index.

significant anticholinergic and sedating effects. A conversion formula to transform scores of MRB-QoL scales into a single overall index or total score has been proposed (see online supplementary file 2). Data were analysed using SPSS Statistics V.22 for windows.

\section{RESULTS}

Three hundred and sixty-seven participants completed the survey and $51.2 \%$ of respondents were male. The median number of prescription medicines and medical condition were 5 and 3, respectively. Most of the respondents were on five or more medicines $(n=200)$ and living with three or more medical conditions $(n=195)$. Exposure to $\mathrm{DBI}>0$ was $52.9 \% \quad(\mathrm{n}=148)$ with a median of 0.9 . Older people ( $\geq 65$ years) accounted for $60.6 \%$ and $47.3 \%$ of patients with DBI $0(n=132)$ and DBI $>0 \quad(n=148)$, respectively. Detailed characteristics of survey respondents are presented in table 1 .

\section{Factor analysis and scales of MRB-QoL measure}

No item had $>5 \%$ missing data. After removing items with low loadings and cross loadings, EFA resulted in a 31-item, five-factor solution which explained $72.1 \%$ of the total variance. Based on the items that constituted each factor, the factors were interpreted as Factor 1: 'Routine and Regimen Complexity' (items 1-11), Factor 2: 'Psychological Burden' (items 12-17), Factor 3: 'Functional and Role Limitation' (items 18-24), Factor 4: 'Therapeutic Relationship' (items 25-27), Factor 5: 'Social Burden' (items 28-31) (table 2). The correlation between factors ranged from 0.33 to 0.57 . In this paper, subscales are used referring to factors. All items of each subscale were reverse coded such that the higher scores reflected higher level of the scale's characteristic (ie, higher burden of medicine and poorer quality of life).

\section{Reliability and characteristics of MRB-QoL}

Internal consistency of the MRB-QoL subscales ranged from 0.87 to 0.95 indicating that all subscales had good internal consistency reliability. ${ }^{42}$ There was no strong evidence of ceiling and floor effects except for the 'Therapeutic Relationship' subscale which had a slightly higher ceiling and the 'Social Burden' subscale which showed a slightly higher floor effect (table 3 ).

\section{Construct validity}

Moderate to high inter-item correlations (range 0.410.85 ) and correlations of items with their own subscales (corrected item-total correlation 0.56-0.93) provided good evidence of internal construct validity of all MRB-QoL subscales.

Both number of medicines and medical conditions were significantly correlated with all subscales of MRB-QoL except in the 'Social Burden' subscale (table 4). Item 13 , which pertained to the number of medicines, was found to have moderate to high correlations $(0.48-0.81)$ with all subscales of MRB-QoL (data not shown). There were weak correlations between MRCI and all subscales of MRB-QoL indicating that MRCI and subscales of MRB-QoL are separate constructs of measures of medication burden (table 4). 'Therapeutic Relationship' and 'Social Burden' subscales of MRB-QoL were inversely correlated with MRCI ( $\mathrm{r}=-0.16$ vs 0.09 ).

DBI score was significantly and positively correlated with all subscales of MRB-QoL (table 4). Moderate correlation between DBI and the 'Functional and Role Limitation' subscale of MRB-QoL provided some evidence of convergent validity, indicating that both DBI and this subscale measure the burden of medicine on functional outcomes. However, the weak magnitude of correlations across the remaining subscales of MRB-QoL (Spearman's rho 0.12 to 0.28 ) demonstrated discriminant validity, indicating that these subscales measure dimensions of medication burden different from that of DBI. The inclusion of 'Pro re nata (PRN)' or 'as needed' medicines did not show significant differences both in the magnitude and direction of correlations (Spearman's rho 0.18 to 0.34). Furthermore, we intended to quantify patient level medication burden by incorporating all the medicines in objective measures (ie, DBI, MRCI) and compare them with patient self-rated MRB-QoL scores. Hence, in this study, PRN medicines (excluding vitamins and herbal medicines) were included in the DBI calculation. Statistically significant but weak and inverse correlations were found between CCI and all subscales of MRB-QoL indicating discriminant validity (table 4 ).

\section{Known groups validity}

Scores of MRB-QoL subscales were compared between subgroups of patients hypothesised to differ (eg, by DBI score, number of medicines and medical conditions). 
Table 2 Factor structure and loadings of the MRB-QoL items

\begin{tabular}{|c|c|c|c|c|c|c|}
\hline \multirow[b]{2}{*}{ S. No. } & \multirow[b]{2}{*}{ Items } & \multicolumn{5}{|c|}{ Factors } \\
\hline & & F1 & F2 & F3 & F4 & F5 \\
\hline 1 & Organising medicine routines (RRC- 1 ) & 0.934 & -0.056 & -0.018 & -0.083 & -0.026 \\
\hline 2 & Keeping medicine record (RRC-2) & 0.913 & -0.007 & -0.053 & -0.069 & -0.046 \\
\hline 3 & Routine-managing (RRC-3) & 0.841 & 0.066 & -0.038 & -0.021 & -0.052 \\
\hline 4 & Fitting medicine routines (RRC-4) & 0.838 & -0.011 & 0.051 & -0.077 & -0.070 \\
\hline 5 & Interference with daily activities (RRC-5) & 0.705 & 0.065 & 0.082 & 0.132 & 0.020 \\
\hline 6 & Balancing-interference (RRC-6) & 0.684 & 0.049 & 0.038 & 0.190 & -0.010 \\
\hline 7 & Simplicity of medicine regimen (RRC-7) & 0.671 & 0.021 & 0.053 & 0.095 & -0.110 \\
\hline 8 & Medicine-instructions (RRC-8) & 0.656 & 0.057 & 0.052 & 0.125 & -0.020 \\
\hline 9 & Regimen-convenience (RRC-9) & 0.651 & 0.030 & -0.005 & 0.023 & -0.207 \\
\hline 10 & Medicine and daily life schedules (RRC-10) & 0.651 & -0.015 & 0.107 & 0.171 & -0.024 \\
\hline 11 & Medicine-package (RRC-11) & 0.535 & 0.050 & 0.087 & 0.131 & 0.141 \\
\hline 12 & Long term-medicine (PsyB-1) & -0.023 & 0.854 & 0.011 & -0.082 & -0.154 \\
\hline 13 & Number of medicines (PsyB-2) & 0.080 & 0.832 & -0.066 & 0.132 & 0.086 \\
\hline 14 & Long term- impact (PsyB-3) & -0.092 & 0.795 & 0.054 & 0.043 & -0.067 \\
\hline 15 & Medicine reminds health condition (PsyB-4) & 0.018 & 0.766 & 0.017 & 0.002 & -0.109 \\
\hline 16 & Medicine-interactions (PsyB-5) & 0.145 & 0.744 & 0.024 & 0.153 & 0.174 \\
\hline 17 & Medicine-signifies problem (PsyB-6) & 0.021 & 0.614 & 0.184 & -0.119 & -0.176 \\
\hline 18 & Sexual relationship (FRL-1) & -0.075 & -0.125 & 0.913 & 0.093 & -0.053 \\
\hline 19 & Sexual activity (FRL-2) & -0.065 & -0.069 & 0.908 & 0.027 & -0.014 \\
\hline 20 & Medicine and physical health (FRL-3) & 0.052 & 0.205 & 0.670 & -0.029 & -0.104 \\
\hline 21 & Medicine and night-sleep (FRL-4) & 0.101 & 0.104 & 0.658 & 0.070 & 0.003 \\
\hline 22 & Medicine and physical activities (FRL-5) & 0.094 & 0.244 & 0.613 & -0.002 & 0.052 \\
\hline 23 & Medicine- impact on work (FRL-6) & 0.265 & 0.036 & 0.609 & 0.019 & -0.064 \\
\hline 24 & Comfort and side effect (FRL-7) & 0.259 & 0.226 & 0.533 & -0.104 & 0.025 \\
\hline 25 & Respect and dignity (TR-1) & 0.005 & -0.019 & 0.067 & 0.826 & -0.085 \\
\hline 26 & Decisions and considerations (TR-2) & 0.012 & 0.104 & 0.021 & 0.804 & -0.088 \\
\hline 27 & Decisions and engagement (TR-3) & 0.108 & 0.036 & 0.037 & 0.757 & -0.049 \\
\hline 28 & Lived experience with others (SB-1) & 0.035 & 0.148 & 0.084 & 0.079 & -0.720 \\
\hline 29 & Public-perception (SB-2) & 0.147 & 0.087 & -0.009 & 0.097 & -0.719 \\
\hline 30 & People and stigma (SB-3) & 0.193 & 0.044 & 0.139 & 0.113 & -0.620 \\
\hline \multirow[t]{3}{*}{31} & Self-stigma (SB-4) & 0.190 & 0.027 & 0.069 & 0.213 & -0.576 \\
\hline & Eigen value & 16.44 & 2.16 & 1.58 & 1.11 & 1.05 \\
\hline & Variance explained & 53.05 & 6.97 & 5.10 & 3.61 & 3.39 \\
\hline
\end{tabular}

Loadings $>0.3$ appear in bold.

F1, Routine and Regimen Complexity (RRC); F2, Psychological Burden (PsyB); F3, Functional and Role Limitation (FRL); F4, Therapeutic Relationship (TR), F5, Social Burden (SB).

MRB-QoL, Medication-Related Burden Quality of Life.

The Mann-Whitney U test was performed to examine differences between subgroups.

Splitting the number of medicines into two groups using $\geq 5$ medicines as a cut-off point for polypharmacy found that both groups were positively correlated with all subscales of MRB-QoL. However, patients with polypharmacy had higher levels of medication burden in all subscales except in the 'Social Burden' subscale (table 5). In contrast, when over-the-counter medicines were excluded from analyses, there was no statistically significant difference in the mean rank score of burden between patients on polypharmacy and those without, in all subscales except in the 'Psychological Burden' subscale. Compared with individuals with no exposure (ie, DBI 0), individuals with exposure to anticholinergic and sedatives (ie, DBI $>0$ ) had significantly higher levels of medication burden in all subscales of MRB-QoL (table 5). However, splitting the data with a DBI cut-off point of 1 (data not 
Table 3 Descriptive statistics and reliabilities for subscales of MRB-QoL measure

\begin{tabular}{lllllrr}
$\begin{array}{l}\text { MRB-QoL subscales } \\
\text { (items) }\end{array}$ & N & Factor-based score (IQR) & Score range & Cronbach's $\boldsymbol{\alpha}$ & \% Floor & \% Ceiling \\
\hline RRC (11 items) & 363 & $24(15-33)$ & $11-55$ & 0.95 & 0.6 & 13.2 \\
PsyB (six items) & 363 & $21(16-24)$ & $6-30$ & 0.91 & 2.8 & 3.3 \\
FRL (seven items) & 351 & $19(14-24)$ & $7-35$ & 0.92 & 1.1 & 1.4 \\
TR (three items) & 367 & $6(4-9)$ & $3-15$ & 0.87 & 19.0 & 24.8 \\
SB (four items) & 358 & $9(6-13)$ & $4-20$ & 0.91 & 1.7 \\
\hline
\end{tabular}

FRL, Functional and Role Limitation; MRB-QoL, Medication-Related Burden Quality of Life; N,number of respondents; PsyB, Psychological Burden; RRC, Routine and Regimen Complexity; SB, Social Burden; TR, Therapeutic Relationship.

shown) did not show a significant difference between patients with DBI $0-1$ versus $\mathrm{DBI}>1$ in any subscales of MRB-QoL except for 'Functional and Role Limitation' $(\mathrm{P}=0.02)$ and 'Psychological Burden' subscales $(\mathrm{P}=0.01)$ where individuals with higher exposure to anticholinergics and sedatives (DBI $>1)$ had also higher levels of medication burden on physical and psychological well-being. Patients with multiple morbidities ( $\geq 3$ different medical conditions) had significantly higher levels of burden in all subscales of MRB-QoL except for the 'Social Burden' subscale (table 5).

Although not part of a priori hypothesis, subgroup analyses by age and gender were conducted. Analysis by age group showed statistically significant differences between younger $(<65$ years) and older $(\geq 65$ years $)$ patients where younger patients had higher scores (ie, poorer quality of life) in all subscales than older ( $\geq 65$ years) adults. In contrast, analysis by gender showed no significant differences between males and females in all subscales except in the 'Therapeutic Relationship' subscale in which males had slightly higher scores.

\section{DISCUSSION}

MRB-QoL is a patient-reported measure specifically designed to evaluate the burden of medicines on quality of life. The results based on a survey of 367 consumers indicated that MRB-QoL has good psychometric properties. All subscales demonstrated high internal consistency. The construct validity of MRB-QoL was demonstrated through its correlation with MRCI and DBI. Further, known group validity of this measure has been demonstrated via its ability to detect differences between subgroups of individuals such as those on polypharmacy, DBI $>0$ and with multimorbidity.

The MRB-QoL tool validated in this study had 31 items grouped into five subscales. The content of MRB-QoL covered various aspects of medication-associated burden. Some items reflected the burden associated with the routines of medicines (eg, items 1, 2, 3, 4, 5, 6, 10) or complexity of medicine regimen (eg, items $7,8,9,11)$ whereas others focused on the burden of medicine on social (eg, items 29, 30, 31), psychological (eg, items 12, $13,14,15,16,17)$ and physical well-being or functioning (eg, items 18, 19, 20, 21, 22, 23, 24). These subscales match well to a priori theoretical conceptual framework and supported by several qualitative research into medication and treatment burden. ${ }^{5} 6{ }^{43-45}$ This indicates the thoroughness in the approach used to inform the development of MRB-QoL. ${ }^{17} 23$ However, three items about financial burden of medicine, which were included in the initial pool of items based on evidence from meta-synthesis data, were dropped from final items following factor analysis (eg, 'I worry about paying medication related expenses'). This may be because the burden of medicine costs might not have been a major concern for the study participants, as the Australian Government has a well-established copayment scheme known as Pharmaceutical Benefit Scheme. Apart from the lack of items about

Table 4 Construct validity of MRB-QoL subscales

\begin{tabular}{|c|c|c|c|c|c|}
\hline \multirow[b]{2}{*}{ MRB-QoL subscales } & \multicolumn{5}{|c|}{ Measures of disease and medicine burden } \\
\hline & $\begin{array}{l}\text { Medical } \\
\text { condition }(n=338)\end{array}$ & $\begin{array}{l}\text { Medicine } \\
\text { number }(n=358)\end{array}$ & MRCI (n=277) & DBI (n=262) & $\mathrm{CCl}(\mathrm{n}=292)$ \\
\hline Routine and Regimen Complexity & $0.11^{*}$ & $0.16^{\star \star *}$ & 0.01 & $0.24^{\star \star \star}$ & $-0.19^{\star \star \star}$ \\
\hline Psychological Burden & $0.14^{\star \star \star}$ & $0.11^{* * *}$ & 0.08 & $0.28^{\star * \star}$ & $-0.15^{\star \star \star}$ \\
\hline Functional and Role Limitation & $0.09^{*}$ & $0.17^{\star \star \star}$ & 0.01 & $0.36^{\star \star *}$ & $-0.23^{\star \star *}$ \\
\hline Therapeutic Relationship & $0.12^{*}$ & $0.20^{\star \star *}$ & $-0.16^{\star \star \star}$ & $0.12^{*}$ & $-0.19^{\star \star \star}$ \\
\hline Social Burden & 0.07 & 0.08 & -0.09 & $0.19^{\star \star \star}$ & $-0.23^{\star \star \star}$ \\
\hline
\end{tabular}

${ }^{*} \mathrm{P}<0.05$, ${ }^{* *} \mathrm{P}<0.001$.

$\mathrm{CCI}$, Charleston's Comorbidity Index; DBI, Drug Burden Index; MRB-QoL, Medication-Related Burden Quality of Life;

$\mathrm{MRCl}$, Medication Regimen Complexity Index. 
Table 5 Known groups validity of MRB-QoL subscales

\begin{tabular}{|c|c|c|c|}
\hline MRB-QoL subscales & Subgroups & Median (IQR) & $\begin{array}{l}\text { Difference between } \\
\text { subgroups: } P \text { value† }\end{array}$ \\
\hline \multirow[t]{9}{*}{ Routine and Regimen Complexity } & All patients $(n=363)$ & $24(15-33)$ & \\
\hline & $\geq 5$ number of medicines $(n=197)$ & $25(17-35)$ & $<0.01^{*}$ \\
\hline & $<5$ number of medicines $(n=161)$ & $23(14-30)$ & \\
\hline & $\geq 3$ conditions $(n=193)$ & $25(17-33)$ & $0.02^{*}$ \\
\hline & $<3$ conditions $(n=168)$ & $22(14-32)$ & \\
\hline & Age <65 $(n=189)$ & $29(22-38)$ & \\
\hline & Male $(n=185)$ & $24(16-34)$ & 0.43 \\
\hline & Female $(n=178)$ & $23(15-33)$ & \\
\hline & DBI $0(n=131)$ & $19(11-28)$ & $<0.01^{*}$ \\
\hline \multirow{9}{*}{ Psychological Burden } & $<5$ number of medicines $(n=162)$ & $20(14-24)$ & \\
\hline & $\geq 3$ conditions $(n=192)$ & $22(17-25)$ & $0.01^{*}$ \\
\hline & $<3$ conditions $(n=169)$ & $19(15-24)$ & \\
\hline & Age >65 years $(n=174)$ & $19(12-22)$ & $<0.01^{*}$ \\
\hline & Age <65 $(n=189)$ & $22(18-25)$ & \\
\hline & Male $(n=185)$ & $21(16-24)$ & 0.74 \\
\hline & Female $(n=178)$ & $21(16-24)$ & \\
\hline & DBI $0(n=131)$ & $19(12-23)$ & $<0.01^{*}$ \\
\hline & $\mathrm{DBI}>0(\mathrm{n}=147)$ & $22(18-25)$ & \\
\hline \multirow{2}{*}{ Functional and Role Limitation } & Age >65 years $(n=174)$ & $16(14-21)$ & $<0.01^{*}$ \\
\hline & Age $<65(n=189)$ & $22(17-28)$ & \\
\hline \multirow[t]{11}{*}{ Therapeutic Relationship } & All patients $(n=367)$ & $6(4-9)$ & \\
\hline & $\geq 5$ number of medicines $(n=200)$ & $6(4-10)$ & $<0.01^{\star}$ \\
\hline & $<5$ number of medicines $(n=162)$ & $6(3-7)$ & \\
\hline & $\geq 3$ conditions $(n=195)$ & $6(4-9)$ & $0.02^{\star}$ \\
\hline & $<3$ conditions $(n=170)$ & $6(3-8)$ & \\
\hline & Age $>65$ years $(n=176)$ & $5(3-6)$ & $<0.01^{\star}$ \\
\hline & Age $<65(n=191)$ & $7(5-10)$ & \\
\hline & Male $(n=183)$ & $6(4-9)$ & $0.04^{\star}$ \\
\hline & Female $(n=175)$ & $6(3-8)$ & \\
\hline & DBI $0(n=132)$ & $6(3-7)$ & $0.02^{*}$ \\
\hline & $\mathrm{DBI}>0(\mathrm{n}=148)$ & $6(4-8)$ & \\
\hline
\end{tabular}


Table 5 Continued

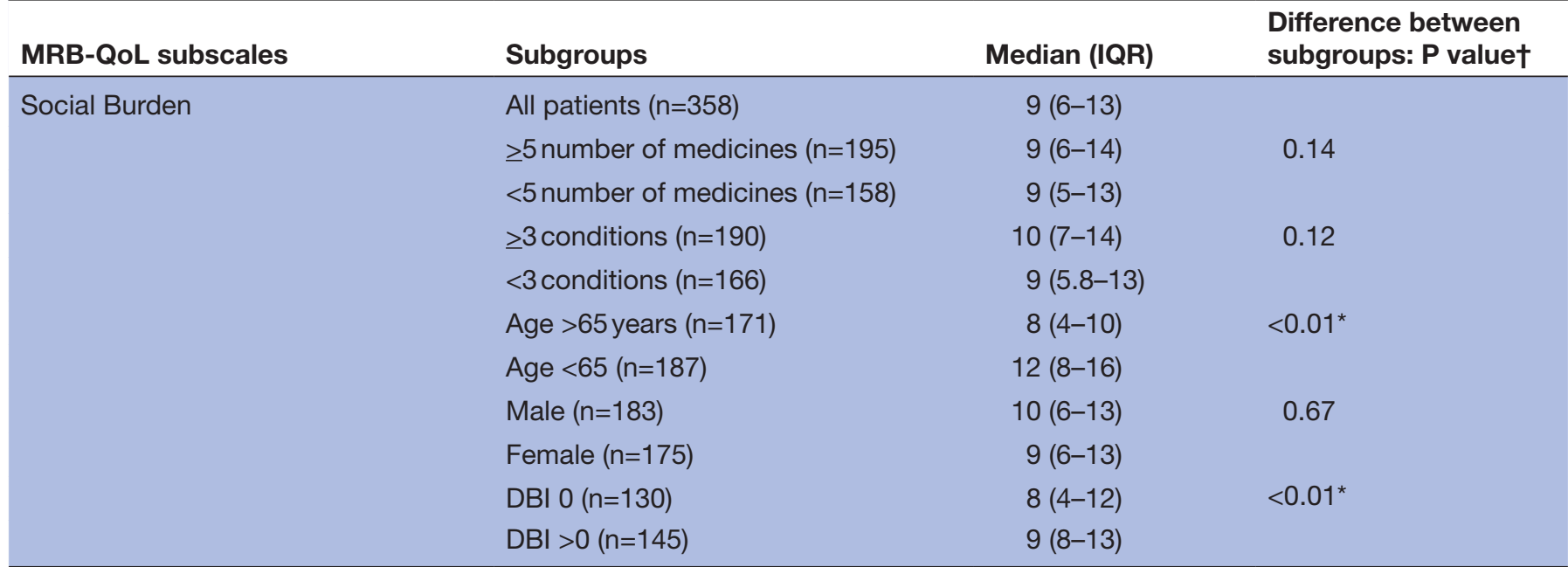

*A $P$ value of 0.05 was considered statistically significant.

$\dagger$ †ifferences between subgroups (mean rank score) were examined using a Mann-Whitney $U$ test. DBI, Drug Burden Index; MRB-QoL, Medication-Related Burden Quality of Life.

financial burden, the comprehensiveness of MRB-QoL is apparent from its concept extending beyond the burden of medicine number (ie, polypharmacy), pharmacological class and nature of medicine regimens.

Correlations between subscales of MRB-QoL and $\mathrm{DBI}^{26}$ and $\mathrm{MRCI}^{27}$ demonstrated the construct validity of the MRB-QoL. The weak correlation between MRB-QoL subscales and the two measures supported a priori hypothesis that MRB-QoL is a separate concept from other measures of medication burden. This difference is clear in that MRB-QoL is multiscale patient self-reported measure of the burden of medicine on quality of life whereas both MRCI and DBI are objective measures of medication burden which quantify the pharmacological 'complexity of medicine regimes ${ }^{\prime 27}$ and cumulative effects of 'exposure to medicines with anticholinergic and sedatives properties', ${ }^{26}$ respectively. This implies usefulness of MRB-QoL as a patient-reported measure in complementing these objective measures of medication burden as it provides a patient's perspective of medication burden. A fairly moderate degree of correlation between DBI and 'Functional and Role Limitation' subscale of MRB-QoL aligns with existing evidence that the DBI is a measure of medication burden related functional decline. ${ }^{26}$ This is also preliminary evidence indicating that 'Functional and Role Limitation' subscale of MRB-QoL is a self-rated measure of functional burden of medication. The correlations between CCI and all subscales of MRB-QoL did not support our a priori hypothesis. However, the inverse correlation perhaps may indicate that when CCI (ie, chance of mortality related to burden of multimorbidity) increases, the more likely patients become overwhelmed by the burden of multimorbidity and may become less concerned about medicine-attributed burden and medication-related quality of life outcomes.
Criterion validity of MRB-QoL has not been evaluated due to the lack of suitable published standard measure of quality of life to compare with MRB-QoL. While MRB-QoL was under development process, few papers on measurement of medicine focused quality of life, ${ }^{46} 47$ treatment burden $^{48-50}$ and 'patients' experiences of prescription medicine use ${ }^{, 51}$ have been published. However, medicine focused quality of life measures were developed in culturally and linguistically different settings. ${ }^{46} 47$ Thus, a direct comparison with MRB-QoL was not possible before they are culturally translated and validated in the English language. Treatment burden instruments, measure 'the impact of healthcare on patients' functioning and wellbeing, ${ }^{48-50}$ including some dimension of medicine; they are however, not specific to the burden of medicine on functioning and well-being. Likewise, despite some similarities between MRB-QoL and measure of medicine use experiences (ie, Living with Medicines Questionnaire) ${ }^{51}$ in their notion of measuring medicine burden, there are, however, basic conceptual, domain and item level differences with MRB-QoL.

\section{Implications for clinical practice and future research}

At present, the complete picture of the benefit of PC services in improving quality of life is not well recognised due to the variability of measures used in the studies. There is also no consensus regarding which HRQoL measure to use for the evaluation of PC services ${ }^{1723}$ and these issues have contributed to the inconsistency of results making demonstration of the benefit PC services on quality of life challenging. ${ }^{17}$ The MRB-QoL has been designed to be an evaluative measure to assess the changes in quality of life related to medicine burden in patients receiving clinical medication reviews or PC interventions. In clinical practice, it may also be used as a diagnostic/screening tool to identify individual patients at high risk of experiencing 
MRB before it adversely affects a patient's quality of life. For example, in the present study, it was found that individuals with higher exposure to medicines with anticholinergic and sedative effects (ie, DBI $>1$ ) had significantly higher levels of burden in the 'Functional and Role Limitation' ( $\mathrm{P}=0.02)$ and 'Psychological Burden' $(\mathrm{P}=0.01)$ subscales of MRB-QoL indicating higher risk for poorer medication-related functional and psychological wellbeing. This finding agrees with previous studies, which reported strong association between high DBI scores and functional impairment particularly in older adults. ${ }^{26}{ }^{52-55}$ Evidence for known group validity also demonstrated that patients with $\mathrm{DBI}>0$, polypharmacy (except in the 'Social Burden' subscale) and multimorbidity had significantly higher levels of burden in all subscales of MRB-QoL implying a greater risk for poorer medication-related quality of life outcomes. While there is strong evidence regarding the association between $\mathrm{DBI}>0,{ }^{26}{ }^{52}$ multimorbidity and quality of life adverse outcomes, there is limited evidence linking the impact of polypharmacy (pill burden) and quality of life outcomes. ${ }^{56}$ This requires further investigation. The contribution of over-thecounter medicines to polypharmacy related medication burden was evident during subgroup analysis for known group validity. This requires the attention of healthcare providers because sometimes patients can have significant burden arising from non-prescription medicines ${ }^{57}$ which is often underappreciated. ${ }^{58}$ Hence, patient-reported measures such as MRB-QoL are of high importance in bringing those issues to healthcare providers' attentions to make informed decision.

Another finding of interest was that there were no significant differences between males and females in their MRB-QoL except in the 'Therapeutic Relationship' subscale where males had a slightly higher score. The absence of significant differences between males and females in Social Burden, Routineand Regimen Complexity, Psychological Burden, Functionaland Role Limitation subscales may imply that generally gender does not influence the way patients perceive the burden of medicine on functioning and well-being. On the other hand, the observed difference in the 'Therapeutic Relationship' subscale may imply that females have a greater tendency to negotiate their care plans with their healthcare providers than males and thus, may have less concern about poor therapeutic relationships. It should be highlighted that despite differences observed in the mean rank scores (ie, Mann-Whitney U test), the median score appeared to be similar. However, the Mann-Whitney test is sensitive to detect the differences in distributions between the groups despite the similarity in the median scores. ${ }^{59}$ Therefore, detection and identification of patients at higher risk of any aspects of MRB (eg, routines, regimen complexity, concern about number or interaction or psychosocial and physical impacts of medicines) is an opportunity for clinicians to engage patients in therapeutic decisions and to individualise interventions to particular aspects of MRB encountered by their patients.

\section{Strengths and limitations}

This study described the development and validation process of the MRB-QoL based on robust methods and highlighted its potential application for research and clinical practice. The development aspects of MRB-QoL such as construct definition and development of the MRB framework, generation of an item pool and psychometric testing were informed by data from patients. The item development was based on 966 quotes of participant's identified through meta-synthesis of 34 qualitative studies. It was anticipated that this approach is more robust than a traditional method of item generation which is restricted to interviews with a single cohort of participants. The development of patient-reported outcome measures using methods other than interviews and focus group discussions have been used in literature ${ }^{60}$ However, qualitative concept-elicitation with consumers may have revealed additional concepts of MRB which were not incorporated in our MRB-QoL tool. Furthermore, cognitive debriefing may have also improved the clarity or content of the MRB-QoL items. Some consumers might have not had their medicines with them when completing the survey or may not have been willing to share information about their medicine and thus, this study may have under-reported information about medicines. This might have also resulted in under-reporting of the DBI and MRCI because only cases with complete information about medicines were considered for calculation. Furthermore, since data were only from patient self-report, it was not possible to comment on the clinical appropriateness or inappropriateness of polypharmacy. A possible limitation of an online survey is only participants who were computer literate and who had access to the internet could participate. It is noteworthy, however, that our study sample did include older people taking multiple medicines. One hundred and seventy-six participants were aged $\geq 65$ years, and the median number of prescription medicines taken was 5 (3-7). Furthermore, the potential sampling bias, of having only computer-literate participants with access to the internet, is unlikely to affect the results of psychometric testing (ie, the factor structure). However, the extent of burden observed in the scores of MRB-QoL subscales and relatively low complexity of medication regimen observed in the MRCI may reflect that participants were well-functioning community dwelling adults. Intensity of the burden in the MRB-QoL, DBI and MRCI may have been different if participants were recruited from hospitals, nursing homes or patients with more complex medicine regimens.

We used a factor-based scores approach, which gives equal weighing to each item in obtaining scores of subscales. This approach is simple and scores obtained by this method can be reliably compared across future studies. However, in the absence of empirical evidence, it is not a sound approach to assume that each item has equal weight in making up a particular subscale. 
Although strong evidence of ceiling and floor effect has not been observed, a slightly high $(>15 \%)^{61}$ ceiling effect in the 'Therapeutic Relationship' and floor effect in the 'social burden' subscales were found. Future investigations could therefore include sensitivity and responsiveness of the MRB-QoL. The initial psychometric testing reported in this paper has set the ground work for future research to look into additional psychometric testing such as confirmatory factor analysis, test-retest reliability, sensitivity and responsiveness of the MRB-QoL. Determining cut-off points for MRB-QoL scores which can be considered as clinically important difference and testing the applicability of MRB-QoL in different populations should also be evaluated.

\section{CONCLUSION}

The MRB-QoLV.1 has good construct validity and internal consistency reliability. The MRB-QoL tool may be a useful humanistic measure for evaluation of the impact of PC interventions on patients' quality of life. Future research is warranted to further examine other psychometric properties of MRB-QoL V.1 and its utility in patient care.

Acknowledgements The authors thank the Survey Sampling International (SSI) research company for conducting online survey of MRB-QoL and all the study participants.

Contributors MAM contributed to the conception and design, analysis and interpretation, drafted and reviewed the manuscript. RJM contributed to the design and interpretation and reviewed the manuscript. SNH and LKO contributed to the interpretation and reviewed the manuscript. TFC contributed to the conception and design, interpretation and reviewed the manuscript.

Competing interests None declared.

Patient consent Obtained.

Ethics approval Human Ethics Committee, The University of Sydney (project number: 2016/654).

Provenance and peer review Not commissioned; externally peer reviewed.

Data sharing statement № additional data are available. The full version of the MRB-QoL V1 is available from MAM (mmoh2116@uni.sydney.edu.au) and TFC ( timothy.chen@sydney.edu.au) on request.

Open Access This is an Open Access article distributed in accordance with the Creative Commons Attribution Non Commercial (CC BY-NC 4.0) license, which permits others to distribute, remix, adapt, build upon this work non-commercially, and license their derivative works on different terms, provided the original work is properly cited and the use is non-commercial. See: http://creativecommons.org/ licenses/by-nc/4.0/

(C) Article author(s) (or their employer(s) unless otherwise stated in the text of the article) 2018. All rights reserved. No commercial use is permitted unless otherwise expressly granted.

\section{REFERENCES}

1. Mohammed MA, Moles RJ, Chen TF. Medication-related burden and patients' lived experience with medicine: a systematic review and metasynthesis of qualitative studies. BMJ Open 2016;6:e010035.

2. Wallace E, Salisbury C, Guthrie B, et al. Managing patients with multimorbidity in primary care. BMJ 2015;350:h176.

3. Matthew M, Murawski JPB. Pharmaceutical therapy-related quality of life: conceptual development. J Soc Adm Pharm 2001;18:2-14.

4. Krska J, Morecroft CW, Poole $\mathrm{H}$, et al. Issues potentially affecting quality of life arising from long-term medicines use: a qualitative study. Int J Clin Pharm 2013;35:1161-9.
5. Tran VT, Barnes C, Montori VM, et al. Taxonomy of the burden of treatment: a multi-country web-based qualitative study of patients with chronic conditions. BMC Med 2015;13:111-115.

6. Sav A, Kendall E, McMillan SS, et al. 'You say treatment, I say hard work': treatment burden among people with chronic illness and their carers in Australia. Health Soc Care Community 2013;21:665-74.

7. Hepler CD, Strand LM. Opportunities and responsibilities in pharmaceutical care. Am J Hosp Pharm 1990;47:533-43.

8. Kheir NM, van Mil JW, Shaw JP, et al. Health-related quality of life measurement in pharmaceutical care. Targeting an outcome that matters. Pharm World Sci 2004;26:125-8.

9. Alldred DP, Raynor DK, Hughes C, et al. Interventions to optimise prescribing for older people in care homes. Cochrane Database Syst Rev 2013:CD009095.

10. de Lyra DP, Kheir N, Abriata JP, et al. Impact of Pharmaceutical Care interventions in the identification and resolution of drugrelated problems and on quality of life in a group of elderly outpatients in Ribeirão Preto (SP), Brazil. Ther Clin Risk Manag 2007;3:989-98.

11. Gourley GA, Portner TS, Gourley DR, et al. Humanistic outcomes in the hypertension and COPD arms of a multicenter outcomes study. J Am Pharm Assoc 1998;38:586-97.

12. Bladh L, Ottosson E, Karlsson J, et al. Effects of a clinical pharmacist service on health-related quality of life and prescribing of drugs: a randomised controlled trial. BMJ Qual Saf 2011;20:738-46.

13. Kheir N, Emmerton L, Shaw J. Can pharmacists influence the healthrelated quality of life of patients with asthma?: The New Zealand Pharmaceutical Care experience. J Sci Res Med Sci 2001;3:69-75.

14. Schulz M, Verheyen F, Mühlig S, et al. Pharmaceutical care services for asthma patients: a controlled intervention study. J Clin Pharmacol 2001;41:668-76.

15. Isetts BJ, Schondelmeyer SW, Heaton AH, et al. Effects of collaborative drug therapy management on patients' perceptions of care and health-related quality of life. Res Social Adm Pharm 2006;2:129-42.

16. Pinto SL, Kumar J, Partha G, et al. Pharmacist-provided medication therapy management (MTM) program impacts outcomes for employees with diabetes. Popul Health Manag 2014;17:21-7.

17. Mohammed MA, Moles RJ, Chen TF. Impact of pharmaceutical care interventions on health-related quality-of-life outcomes: a systematic review and meta-analysis. Ann Pharmacother 2016;50:862-81.

18. Viswanathan M, Kahwati LC, Golin CE, et al. Medication therapy management interventions in outpatient settings: a systematic review and meta-analysis. JAMA Intern Med 2015;175:76-87.

19. Malone DC, Carter BL, Billups SJ, et al. Can clinical pharmacists affect SF-36 scores in veterans at high risk for medication-related problems? Med Care 2001;39:113-22.

20. Holland R, Desborough J, Goodyer L, et al. Does pharmacist-led medication review help to reduce hospital admissions and deaths in older people? a systematic review and meta-analysis. Br J Clin Pharmacol 2008;65:303-16.

21. Jarab AS, Alqudah SG, Khdour M, et al. Impact of pharmaceutical care on health outcomes in patients with COPD. Int J Clin Pharm 2012;34:53-62.

22. Volume $\mathrm{Cl}$, Farris $\mathrm{KB}$, Kassam R, et al. Pharmaceutical care research and education project: patient outcomes. J Am Pharm Assoc 2001:41:411-20.

23. Mohammed MA, Moles RJ, Chen TF. Pharmaceutical care and Health Related Quality of Life (HRQoL) outcomes over the past 25 years: have we measured dimensions that really matter? Int Journal Cl Pharm 2017.

24. Pickard AS, Hung SY. An update on evidence of clinical pharmacy services' impact on health-related quality of life. Ann Pharmacother 2006;40:1623-34.

25. Pickard AS, Johnson JA, Farris KB. The impact of pharmacist interventions on health-related quality of life. Ann Pharmacother 1999;33:1167-72.

26. Hilmer SN, Mager DE, Simonsick EM, et al. A drug burden index to define the functional burden of medications in older people. Arch Intern Med 2007;167:781-7.

27. George J, Phun YT, Bailey MJ, et al. Development and validation of the medication regimen complexity index. Ann Pharmacother 2004;38:1369-76.

28. Fidell Linda S, Tabachnick Barbara G, eds. Using multivariate statistics. 5th edn. Boston: Allyn and Bacon, 2007:345-436.

29. Bryant FB, Yarnold PR. Principal components analysis and exploratory and confirmatory factor analysis. In: Grimm LG, Yarnold PR, eds. Reading and understanding multivariate statistics. Washington, DC: APA, 1995:99-136.

30. Pedhazur EJ, Schmelkin LP. Measurement,design, and analysis. Hillsdale, NJ: Lawrence Erlbaum Associates, 1991. 
31. Pett MA, Lackey NR, Sullivan JJ. Making sense of factor analysis. Thousand Oaks, CA: Sage Publications, 2003.

32. Cronbach LJ. Coefficient alpha and the internal structure of tests. Psychometrika 1951:16:297-334.

33. Cohen J. Statistical power analysis for the behavioral sciences. 2nd edn. Hillsdale, NJ: Lawrence Erlbaum Associates, 1988.

34. Gnjidic D, Hilmer SN, Blyth FM, et al. Polypharmacy cutoff and outcomes: five or more medicines were used to identify communitydwelling older men at risk of different adverse outcomes. J Clin Epidemiol 2012;65:989-95.

35. Mavaddat N, Valderas JM, van der Linde R, et al. Association of self-rated health with multimorbidity, chronic disease and psychosocial factors in a large middle-aged and older cohort from general practice: a cross-sectional study. BMC Fam Pract 2014;15:185.

36. Fortin M, Hudon C, Haggerty J, et al. Prevalence estimates of multimorbidity: a comparative study of two sources. BMC Health Serv Res 2010;10:111.

37. Harrison $\mathrm{C}$, Britt $\mathrm{H}$, Miller $\mathrm{G}$, et al. Examining different measures of multimorbidity, using a large prospective cross-sectional study in Australian general practice. BMJ Open 2014;4:e004694.

38. Lowe DB, Taylor MJ, Hill SJ. Cross-sectional examination of musculoskeletal conditions and multimorbidity: influence of different thresholds and definitions on prevalence and association estimates. BMC Res Notes 2017;10:51.

39. van den Bussche $\mathrm{H}$, Koller D, Kolonko T, et al. Which chronic diseases and disease combinations are specific to multimorbidity in the elderly? results of a claims data based cross-sectional study in Germany. BMC Public Health 2011;11:101.

40. Best O, Gnjidic D, Hilmer SN, et al. Investigating polypharmacy and drug burden index in hospitalised older people. Intern Med $\mathrm{J}$ 2013;43:912-8.

41. Gnjidic D, Cumming RG, Le Couteur DG, et al. Drug Burden Index and physical function in older Australian men. Br J Clin Pharmacol 2009;68:97-105

42. Nunnally JO. Psychometric theory. New York: McGraw-Hill, 1978.

43. Demain S, Gonçalves AC, Areia C, et al. Living with, managing and minimising treatment burden in long term conditions: a systematic review of qualitative research. PLoS One 2015;10:e0125457.

44. Rosbach M, Andersen JS. Patient-experienced burden of treatment in patients with multimorbidity - a systematic review of qualitative data. PLoS One 2017;12:e0179916.

45. Sav A, King MA, Whitty JA, et al. Burden of treatment for chronic illness: a concept analysis and review of the literature. Health Expect 2015:18:312-24.

46. Sakthong P, Suksanga P, Sakulbumrungsil R, et al. Development of Patient-reported Outcomes Measure of Pharmaceutical Therapy for
Quality of Life (PROMPT-QoL): a novel instrument for medication management. Res Social Adm Pharm 2015;11:315-38.

47. Tseng HM, Lee CH, Chen YJ, et al. Developing a measure of medication-related quality of life for people with polypharmacy. Qual Life Res 2016;25:1295-302.

48. Tran VT, Harrington M, Montori VM, et al. Adaptation and validation of the Treatment Burden Questionnaire (TBQ) in English using an internet platform. BMC Med 2014;12:109.

49. Eton DT, Yost KJ, Lai JS, et al. Development and validation of the Patient Experience with Treatment and Self-management (PETS): a patient-reported measure of treatment burden. Qual Life Res 2017;26:489-503.

50. Tran VT, Montori VM, Eton DT, et al. Development and description of measurement properties of an instrument to assess treatment burden among patients with multiple chronic conditions. BMC Med 2012;10:68

51. Krska J, Katusiime B, Corlett SA. Validation of an instrument to measure patients' experiences of medicine use: the living with medicines questionnaire. Patient Prefer Adherence 2017;11:671-9.

52. Gnjidic D, Bell JS, Hilmer SN, et al. Drug Burden Index associated with function in community-dwelling older people in Finland: a crosssectional study. Ann Med 2012;44:458-67.

53. Hilmer SN, Mager DE, Simonsick EM, et al. Drug burden index score and functional decline in older people. Am J Med 2009;122:1142-9.

54. Lowry E, Woodman RJ, Soiza RL, et al. Drug burden index, physical function, and adverse outcomes in older hospitalized patients. J Clin Pharmacol 2012;52:1584-91.

55. Kouladjian L, Gnjidic D, Chen TF, et al. Drug Burden Index in older adults: theoretical and practical issues. Clin Interv Aging 2014;9:1503-15.

56. Lalic S, Jamsen KM, Wimmer BC, et al. Polypharmacy and medication regimen complexity as factors associated with staff informant rated quality of life in residents of aged care facilities: a cross-sectional study. Eur J Clin Pharmacol 2016;72:1117-24.

57. Lees J. Management of polypharmacy in older cancer patients. Cancer Forum 2013;37:230-3.

58. Turner JP, Jamsen KM, Shakib S, et al. Polypharmacy cut-points in older people with cancer: how many medications are too many? Support Care Cancer 2016;24:1831-40.

59. Hart A. Mann-Whitney test is not just a test of medians: differences in spread can be important. BMJ 2001;323:391-3.

60. Wiering B, de Boer D, Delnoij D. Patient involvement in the development of patient-reported outcome measures: a scoping review. Health Expect 2017;20:11-23.

61. Terwee CB, Bot SD, de Boer MR, et al. Quality criteria were proposed for measurement properties of health status questionnaires. $J$ Clin Epidemiol 2007;60:34-42. 